\title{
FEATURES OF PSYCHOPATHOLOGICAL REACTION IN PARENTS WHOSE CHILDREN SUFFER FROM CHRONIC MUSCULOSKELETAL DISORDERS
}

DOI: 10.36740/WLek202109121

\author{
Oleksandr Belov, Yevhen Loiko, Iryna Mazaikina, Iryna Pototska \\ NATIONAL PIROGOV MEMORIAL MEDICAL UNIVERSITY, VINNYTSIA, UKRAINE
}

\begin{abstract}
The aim: Was exploring features of psychopathological reaction in parents whose children suffer from chronic musculoskeletal disorders.

Materials and methods: Clinically, 40 fathers and 64 mothers of children suffering from chronic muscular motor pathologies using M. Hamilton's Depression and Anxiety Scale and Buss-Durkee Hostility Invertory were examined.

Results: It was revealed that the foundation of psychopathological reactions of parents to the chronic illness of children is depressive (from 68,2\% to $97,0 \%$ ) and anxiety (from 40.9\% to 100.0\%) disorders, and dyssomic disorders as well (from 18.2\% to 93.9\%), asthenic (from 9.1\% to 81.8.\%), affective lability (from 9.1\% to $36.4 \%$ ), apathetic (from $4.5 \%$ to 42.4\%), cognitive (from 4.5\% to 42.4\%) and obsessive-phobic (from 4.5\% to $39.4 \%$ ) disorders. Mothers with longer and shorter periods of illness in children showed higher levels of depression ( $20.82 \pm 5.94$ and $20.26 \pm 6.59$ respectively) and anxiety (19.06 \pm 5.00 and $17,77 \pm 5.65)$ compared with fathers (17.44 \pm 8.78 and $10.82 \pm 6.21$, respectively; $14.72 \pm 5.57$ and $14.95 \pm 4.45$ ), but fathers showed higher levels of aggression $65.59 \pm 10.42$ and $63.21 \pm 10.31$ (respectively versus $55.27 \pm 6.97$ and $49.72 \pm 10.00$ ). Conclusions: A high level of psychopathological reaction in mothers is detected at short periods of disease, and in fathers it significantly grows as the duration of child's illness increases.
\end{abstract}

KEY WORDS: psychopathological reactions in parents, chronic illnesses in children, depression, anxiety, aggression

Wiad Lek. 2021;74(9 p.l):2147-2151

\section{INTRODUCTION}

Severe illnesses in children are stressful for parents and can lead to the impairment of normal mental functioning [1, 2]. Modern research has revealed a wide range of psychopathological disorders in parents of seriously ill children, including post-traumatic stress disorder, anxious and dyssomnic depressive disorders [3,4]; mothers of sick children are especially susceptible to such unfavorable changes $[5$, 6]. A number of studies emphasize the complex nature of the psychopathological reaction of parents to a serious illness in children, in pathogenesis of which medical, psychosocial and demographic factors are important, as well as the interconnection of child and parental manifestations of psychopathology $[7,8]$. At the same time, there is not enough research on psychological reactions of parents to various severe diseases of children, and the relevance of developing programs for adaptation and psychological assistance to parents of seriously ill children on the basis of scientific research $[9,10]$.

\section{THE AIM}

The aim of research was to study characteristics of psychopathological reaction in parents whose children suffer from chronic diseases of musculoskeletal system.

\section{MATERIALS AND METHODS}

Observing principles of biomedical ethics, 104 parents were clinically examined (40 fathers and 64 mothers) of 64 children suffering from chronic diseases of musculoskeletal system, having received medical treatment at Vinnitsa Regional Children's Clinical Hospital in the period from 2017 to 2020. The nosological structure of children's diseases was represented by spinal injuries consequences (60.9\%), congenital malformations of musculoskeletal system (18.8\%), joint contractures (17.2\%) and osteopathy (3.1\%). Among examined fathers and mothers two groups of the study were distinguished depending on duration of child's disease: the first group (F1) included fathers of children with a disease duration of up to one year (average age $34.2 \pm 3.4$ years, average duration of the disease in child $7.6 \pm 3.0$ months), in the second (M1) - mothers of children with a disease duration of up to one year $(32.3 \pm 2.1$ years and $9.2 \pm 3.1$ months respectively), in the third (F2) - fathers of children with a disease duration of more than one year $(43.3 \pm 5.9$ years and $30.4 \pm 16.0$ months respectively); in the fourth (M2) mothers of children with a disease duration of more than one year (37.4 \pm 4.1 years and $35.2 \pm 10.3$ months respectively).

The study was conducted using M. Hamilton's Depression [11] and Anxiety Scale [12] (HDRS and HARS) and BussDurkee Hostility Invertory (BDHI) [13]. 
Table I. Structure of psychopathological in patients of children suffering from chronic diseases of the musculoskeletal system

\begin{tabular}{|c|c|c|c|c|c|c|c|c|}
\hline \multirow{3}{*}{ Indicators } & \multicolumn{8}{|c|}{ Groups } \\
\hline & \multicolumn{2}{|l|}{$\mathbf{F 1}$} & \multicolumn{2}{|c|}{ M1 } & \multicolumn{2}{|c|}{$\mathbf{F 2}$} & \multicolumn{2}{|r|}{ M2 } \\
\hline & abs. & $\%$ & abs. & $\%$ & abs. & $\%$ & abs. & $\%$ \\
\hline Lowmood & 15 & 68,2 & 29 & 93,5 & 14 & 77,8 & 32 & 97,0 \\
\hline Anxious or fear & 9 & 40,9 & 29 & 93,5 & 12 & 66,7 & 33 & 100 \\
\hline Mood irritable and mood variation & 2 & 9,1 & 11 & 35,5 & 12 & 66,7 & 12 & 36,4 \\
\hline Fast fatigability & 2 & 9,1 & 6 & 19,4 & 9 & 50,0 & 27 & 81,8 \\
\hline Apathy & 1 & 4,5 & 2 & 6,5 & 3 & 16,7 & 14 & 42,4 \\
\hline Obsessive thoughts & 1 & 4,5 & 8 & 25,8 & 2 & 11,1 & 13 & 39,4 \\
\hline $\begin{array}{l}\text { Lowed concentration / decision } \\
\text { making }\end{array}$ & 1 & 4,5 & 3 & 9,7 & 5 & 27,8 & 14 & 42,4 \\
\hline Dyssomnia & 4 & 18,2 & 21 & 67,7 & 9 & 50,0 & 31 & 93,9 \\
\hline \multicolumn{9}{|c|}{ level of statistical significance of differences (p) } \\
\hline \multirow[b]{2}{*}{ Indicators } & \multicolumn{8}{|c|}{ Groups that are compared } \\
\hline & F1 vs M1 & & F2 vs M2 & & & F1 vs F2 & & M1 vs M2 \\
\hline Lowmood & 0,020 & & 0,047 & & & 0,377 & & 0,476 \\
\hline Anxious or fear & 0,000 & & 0,001 & & & 0,096 & & 0,231 \\
\hline Mood irritable and mood variation & 0,027 & & 0,037 & & & 0,000 & & 0,575 \\
\hline Fast fatigability & 0,266 & & 0,021 & & & 0,005 & & 0,000 \\
\hline Apathy & 0,629 & & 0,058 & & & 0,230 & & 0,001 \\
\hline Obsessive thoughts & 0,044 & & 0,032 & & & 0,423 & & 0,187 \\
\hline $\begin{array}{l}\text { Lowed concentration / decision } \\
\text { making }\end{array}$ & 0,445 & & 0,234 & & & 0,054 & & 0,003 \\
\hline Dyssomnia & 0,000 & & 0,001 & & & 0,036 & & 0,008 \\
\hline
\end{tabular}

Statistical analysis of differences between groups was performed using non-parametric Mann-Whitney U test and Fisher exact test.

\section{RESULTS}

The results of analysis of the structure of psychopathological symptoms in studied groups are shown in Table I.

As the Table shows, the structure of psychopathological symptoms in fathers and mothers varied significantly. In general, the dominant symptoms in parents were low mood and anxiety; at the same time, in mothers they were detected much more often and appeared already at short periods of illness in children, while in fathers the prevalence of anxiety-depressive phenomena was significantly lower, and considerably increased with a prolonged disease in children. The percentage of symptoms such as fatigue and sleep disorders significantly elevates with an increase in the duration of disease in both fathers and mothers; manifestations of emotional lability - in fathers, and cognitive impairments - in mothers. However, the prevalence of emotional lability, obsessive disorders and sleep disorders in mothers is significantly higher than in fathers both in groups with short and prolonged periods of disease in children, and increased fatigue in group with prolonged periods of disease.
The analysis of severity of depressive and anxious symptoms using standard HDRS and HARS scales revealed certain patterns (Table II).

In general, maternal depression rates are higher than those expressed in fathers; this difference is most noticeable with short-term disease in children. With a prolonged disease, the tendency towards higher levels of depression in mothers persists, but the differences with fathers are not statistically significant. The mothers showed higher levels of adynamic depression, agitation depression and depression with fear. The level of undifferentiated depression was slightly higher in fathers of children with a prolonged disease; however, these differences are not statistically significant. The general tendency was a significantly more pronounced increase in both the general indicator of depression and the indicators of its individual types with an increase in disease duration in children, while in mothers the indicators of depression were initially high and did not change significantly with an increase in disease duration.

Somewhat different patterns are characteristic of anxiety manifestations. Indicators of anxiety are also higher in mothers, and its indicators slightly increase with disease duration; in fathers, the indicators of anxiety in the group with a prolonged course of the disease were 
Table II. Indicators of depressive and anxiety symptoms in parents of children suffering from chronic diseases of musculoskeletal system (in scores)

\begin{tabular}{|c|c|c|c|c|c|c|c|c|}
\hline Indicators & $\begin{array}{c}F 1 \\
M \pm m / M e \\
\left(Q_{25}-Q_{75}\right) \\
\end{array}$ & $\begin{array}{c}M 1 \\
M \pm m / M e \\
\left(Q_{25}-Q_{75}\right) \\
\end{array}$ & $\begin{array}{c}p \\
\text { F1 vs } M 1\end{array}$ & $\begin{array}{c}F 2 \\
M \pm m / M e \\
\left(Q_{25}-Q_{75}\right) \\
\end{array}$ & $\begin{array}{c}M 2 \\
M \pm m / M e \\
\left(Q_{25}-Q_{75}\right) \\
\end{array}$ & $\stackrel{p}{\text { F2vsM2 }}$ & $\stackrel{p}{\text { F1 vs F2 }}$ & $\underset{\text { M1 vsM2 }}{p}$ \\
\hline \multicolumn{9}{|c|}{ M. Hamilton'sDepressionScale (HDRS) } \\
\hline Total score & $\begin{array}{c}10,82 \pm 6,21 \\
/ 8,50 \\
(7,00-17,00)\end{array}$ & $\begin{array}{c}20,26 \pm 6,59 \\
/ 22,00 \\
(17,00-26,00)\end{array}$ & 0,000 & $\begin{array}{c}17,44 \pm 8,78 \\
/ 21,00 \\
(10,00-24,00)\end{array}$ & $\begin{array}{c}20,82 \pm 5,94 \\
/ 23,00 \\
(17,00-26,00)\end{array}$ & 0,228 & 0,009 & 0,840 \\
\hline $\begin{array}{l}\text { Adynamic } \\
\text { depression }\end{array}$ & $\begin{array}{c}7,36 \pm 3,77 \\
/ 7,00 \\
(4,00-10,00)\end{array}$ & $\begin{array}{c}13,16 \pm 3,70 \\
/ 14,00 \\
(10,00-16,00)\end{array}$ & 0,000 & $\begin{array}{c}11,72 \pm 5,61 \\
/ 13,00 \\
(6,00-16,00)\end{array}$ & $\begin{array}{c}13,52 \pm 3,72 \\
/ 15,00 \\
(11,00-16,00)\end{array}$ & 0,333 & 0,013 & 0,686 \\
\hline $\begin{array}{l}\text { Agitation } \\
\text { depression }\end{array}$ & $\begin{array}{c}3,64 \pm 2,89 \\
/ 3,00 \\
(1,00-6,00)\end{array}$ & $\begin{array}{c}11,00 \pm 4,32 \\
/ 12,00 \\
(8,00-15,00)\end{array}$ & 0,000 & $\begin{array}{c}6,89 \pm 4,27 \\
/ 7,50 \\
(3,00-11,00)\end{array}$ & $\begin{array}{c}11,67 \pm 3,75 \\
/ 13,00 \\
(9,00-14,00)\end{array}$ & 0,000 & 0,015 & 0,575 \\
\hline $\begin{array}{l}\text { Depression with } \\
\text { fear }\end{array}$ & $\begin{array}{c}5,05 \pm 2,59 \\
/ 4,00 \\
(3,00-7,00)\end{array}$ & $\begin{array}{c}11,16 \pm 3,77 \\
/ 11,00 \\
(9,00-15,00)\end{array}$ & 0,000 & $\begin{array}{c}7,17 \pm 4,15 \\
/ 8,00 \\
(4,00-10,00)\end{array}$ & $\begin{array}{c}11,61 \pm 3,45 \\
/ 12,00 \\
(9,00-14,00)\end{array}$ & 0,001 & 0,087 & 0,798 \\
\hline $\begin{array}{l}\text { Undifferentiated } \\
\text { depression }\end{array}$ & $\begin{array}{c}2,50 \pm 2,32 \\
/ 1,50 \\
(1,00-4,00)\end{array}$ & $\begin{array}{c}4,29 \pm 1,99 \\
/ 4,00 \\
(3,00-6,00)\end{array}$ & 0,005 & $\begin{array}{c}4,72 \pm 2,85 \\
/ 6,50 \\
(2,00-7,00)\end{array}$ & $\begin{array}{c}4,48 \pm 2,05 \\
/ 5,00 \\
(3,00-6,00)\end{array}$ & 0,498 & 0,016 & 0,694 \\
\hline \multicolumn{9}{|c|}{ M. Hamilton'sAnxietyScale (HARS) } \\
\hline Total score & $\begin{array}{c}14,95 \pm 4,45 \\
/ 14,00 \\
(12,00-18,00)\end{array}$ & $\begin{array}{c}17,77 \pm 5,65 \\
/ 18,00 \\
(13,00-20,00) \\
\end{array}$ & 0,072 & $\begin{array}{c}14,72 \pm 5,57 \\
/ 15,00 \\
(10,00-20,00)\end{array}$ & $\begin{array}{c}19,06 \pm 5,00 \\
/ 20,00 \\
(15,00-22,00)\end{array}$ & 0,017 & 0,827 & 0,261 \\
\hline Psychical anxiety & $\begin{array}{c}5,55 \pm 2,94 / \\
5,50 \\
(3,00-8,00)\end{array}$ & $\begin{array}{c}12,52 \pm 3,90 \\
/ 13,00 \\
(9,00-16,00)\end{array}$ & 0,000 & $\begin{array}{c}8,17 \pm 3,88 \\
/ 8,50 \\
(5,00-11,00)\end{array}$ & $\begin{array}{c}12,88 \pm 3,67 \\
/ 13,00 \\
(10,00-16,00)\end{array}$ & 0,000 & 0,028 & 0,676 \\
\hline Somatic anxiety & $\begin{array}{c}9,41 \pm 2,40 \\
/ 9,00 \\
(8,00-11,00)\end{array}$ & $\begin{array}{c}5,26 \pm 3,35 \\
/ 5,00 \\
(2,00-8,00)\end{array}$ & 0,000 & $\begin{array}{c}6,56 \pm 2,79 \\
/ 6,00 \\
(4,00-9,00)\end{array}$ & $\begin{array}{c}6,18 \pm 3,84 \\
/ 5,00 \\
(4,00-7,00)\end{array}$ & 0,497 & 0,005 & 0,371 \\
\hline
\end{tabular}

slightly lower. In general, mothers showed higher levels of mental anxiety, while fathers showed higher levels of somatic anxiety.

Interesting features were identified when analyzing the manifestations of aggressiveness (Table III).

Generally, a higher level of aggressiveness was peculiar to fathers: indicators of physical aggression, irritation and general index of aggressiveness both in group with short and long periods of disease in children, as well as indirect aggression and resentment in group with long-term period of disease significantly prevailed. The indicators of negativism, verbal aggression and aggressiveness in fathers were also slightly higher than those of mothers, but the differences are not statistically significant. In general, the indicators of indirect aggression, irritation, negativism, resentment, verbal aggression and the index of aggressiveness were higher in the group with prolonged disease periods in children, while the indicators of physical aggression, suspicion, feelings of guilt and hostility are somewhat lower. In mothers, indicators of physical aggression, irritation, resentment, verbal aggression, feelings of guilt and the general index of aggressiveness in group with prolonged disease periods are higher, whereas indicators of indirect aggression, negativism, suspicion and hostility are slightly lower than in the group with short disease periods, but the differences are statistically significant only for irritability and the general aggression model.

\section{DISCUSSION}

The study made it possible to identify some features of psychopathological reaction in parents whose children suffer from chronic diseases of the musculoskeletal system.

More severe manifestations of depressive and anxiety disorders in mothers identified in our study as compared to fathers are consistent with the data of earlier studies [3, $4,5,6]$; at the same time, it was found that high levels of depression and anxiety in mothers are detected already in the early stages of the disease in children, and persist with a prolonged course, while fathers initially had lower levels of depression and anxiety, which significantly increased with disease duration of children $[7,8]$.

Manifestations of other types of psychopathological symptoms (asthenic, obsessive, cognitive, dyssomnic) naturally grow with an increase in disease duration, which can be regarded as manifestations of neurotization. For fathers of children with a longer disease duration, the prevalence of psychopathological symptoms was more significant compared 
Table III. BDHI indicators in parents of children suffering from chronic diseases of musculoskeletal system (inscores)

\begin{tabular}{|c|c|c|c|c|c|c|c|c|}
\hline Indicators & $\begin{array}{c}F 1 \\
M \pm m / M e \\
\left(Q_{25}-Q_{75}\right) \\
\end{array}$ & $\begin{array}{c}M 1 \\
M \pm m / M e \\
\left(Q_{25}-Q_{75}\right) \\
\end{array}$ & $\underset{\text { F1 vs M1 }}{p}$ & $\begin{array}{c}F 2 \\
M \pm m / M e \\
\left(Q_{25}-Q_{75}\right)\end{array}$ & $\begin{array}{c}M 2 \\
M \pm m / M e \\
\left(Q_{25}-Q_{75}\right) \\
\end{array}$ & $\begin{array}{c}p \\
\text { F2 vs M2 }\end{array}$ & $\underset{\text { F1 vs F2 }}{p}$ & $\underset{\text { M1 vs M2 }}{p}$ \\
\hline Physical aggression & $\begin{array}{c}35,91 \pm 8,54 \\
/ 40,00 \\
(30,00-40,00)\end{array}$ & $\begin{array}{c}26,13 \pm 9,19 \\
/ 20,00 \\
(20,00-30,00)\end{array}$ & 0,000 & $\begin{array}{c}35,56 \pm 10,97 \\
/ 40,00 \\
(30,00-40,00)\end{array}$ & $\begin{array}{c}28,48 \pm 9,06 \\
/ 30,00 \\
(20,00-30,00)\end{array}$ & 0,029 & 0,989 & 0,181 \\
\hline Indirect aggression & $\begin{array}{c}45,09 \pm 10,04 \\
/ 44,00 \\
(40,00-56,00)\end{array}$ & $\begin{array}{c}39,23 \pm 12,96 \\
/ 40,00 \\
(32,00-48,00)\end{array}$ & 0,101 & $\begin{array}{c}51,11 \pm 17,38 \\
/ 56,00 \\
(40,00-64,00)\end{array}$ & $\begin{array}{c}36,85 \pm 14,55 \\
/ 32,00 \\
(24,00-48,00)\end{array}$ & 0,006 & 0,113 & 0,367 \\
\hline Irritation & $\begin{array}{c}77,50 \pm 21,86 \\
/ 82,50 \\
(66,00-88,00)\end{array}$ & $\begin{array}{c}56,77 \pm 15,32 \\
/ 55,00 \\
(44,00-66,00)\end{array}$ & 0,001 & $\begin{array}{c}82,50 \pm 18,58 \\
/ 88,00 \\
(66,00-88,00)\end{array}$ & $\begin{array}{c}66,00 \pm 18,85 \\
/ 66,00 \\
(55,00-88,00)\end{array}$ & 0,008 & 0,531 & 0,043 \\
\hline Negativism & $\begin{array}{c}67,27 \pm 16,95 \\
/ 60,00 \\
(60,00-80,00)\end{array}$ & $\begin{array}{c}61,29 \pm 26,30 \\
/ 60,00 \\
(40,00-80,00)\end{array}$ & 0,316 & $\begin{array}{c}70,00 \pm 20,86 \\
/ 70,00 \\
(60,00-80,00)\end{array}$ & $\begin{array}{c}57,58 \pm 25,38 \\
/ 60,00 \\
(40,00-80,00)\end{array}$ & 0,098 & 0,641 & 0,619 \\
\hline Resentment & $\begin{array}{c}43,77 \pm 14,24 \\
/ 45,00 \\
(27,00-54,00)\end{array}$ & $\begin{array}{c}36,87 \pm 16,81 \\
/ 36,00 \\
(27,00-45,00)\end{array}$ & 0,184 & $\begin{array}{c}44,50 \pm 13,27 \\
/ 45,00 \\
(45,00-54,00)\end{array}$ & $\begin{array}{c}38,45 \pm 12,78 \\
/ 45,00 \\
(36,00-45,00)\end{array}$ & 0,048 & 0,759 & 0,635 \\
\hline Suspicion & $\begin{array}{c}63,18 \pm 15,85 \\
/ 70,00 \\
(50,00-70,00)\end{array}$ & $\begin{array}{c}56,77 \pm 18,15 \\
/ 60,00 \\
(50,00-70,00)\end{array}$ & 0,167 & $\begin{array}{c}54,44 \pm 8,56 \\
/ 50,00 \\
(50,00-60,00)\end{array}$ & $\begin{array}{c}53,33 \pm 17,26 \\
/ 50,00 \\
(40,00-70,00)\end{array}$ & 0,863 & 0,007 & 0,432 \\
\hline Verbal aggression & $\begin{array}{c}76,23 \pm 12,23 \\
/ 78,00 \\
(65,00-91,00)\end{array}$ & $\begin{array}{c}66,26 \pm 21,06 / \\
78,00 \\
(39,00-78,00)\end{array}$ & 0,106 & $\begin{array}{c}78,72 \pm 13,72 \\
/ 84,50 \\
(65,00-91,00)\end{array}$ & $\begin{array}{c}71,30 \pm 14,94 \\
/ 78,00 \\
(65,00-78,00)\end{array}$ & 0,092 & 0,502 & 0,356 \\
\hline Guilt & $\begin{array}{c}64,50 \pm 15,29 \\
/ 66,00 \\
(55,00-77,00)\end{array}$ & $\begin{array}{c}64,58 \pm 11,27 \\
/ 66,00 \\
(55,00-77,00)\end{array}$ & 0,896 & $\begin{array}{c}62,94 \pm 13,50 \\
/ 55,00 \\
(55,00-77,00)\end{array}$ & $\begin{array}{c}68,00 \pm 14,67 \\
/ 77,00 \\
(55,00-77,00)\end{array}$ & 0,237 & 0,768 & 0,299 \\
\hline $\begin{array}{l}\text { Aggressiveness } \\
\text { index }\end{array}$ & $\begin{array}{c}63,21 \pm 10,31 \\
/ 65,30 \\
(53,30-72,00)\end{array}$ & $\begin{array}{c}49,72 \pm 10,00 \\
/ 47,30 \\
(45,00-55,70)\end{array}$ & 0,000 & $\begin{array}{c}65,59 \pm 10,42 \\
/ 65,00 \\
(54,00-73,00)\end{array}$ & $\begin{array}{c}55,27 \pm 6,97 \\
/ 56,70 \\
(50,70-58,00)\end{array}$ & 0,001 & 0,496 & 0,012 \\
\hline Hostility index & $\begin{array}{c}53,48 \pm 12,67 \\
/ 57,00 \\
(38,50-62,00)\end{array}$ & $\begin{array}{c}46,82 \pm 14,44 \\
/ 52,50 \\
(30,00-56,50)\end{array}$ & 0,056 & $\begin{array}{c}49,47 \pm 8,61 \\
/ 52,00 \\
(42,50-57,00)\end{array}$ & $\begin{array}{c}45,89 \pm 10,80 \\
/ 52,00 \\
(38,50-53,00)\end{array}$ & 0,417 & 0,074 & 0,691 \\
\hline
\end{tabular}

with fathers of children with a shorter disease duration, while these differences were less marked in mothers. Fathers (to a considerable degree) and mothers of seriously ill children are characterized by high levels of aggressiveness and hostility; at the same time, individual components of aggressiveness have revealed complex patterns depending on gender, which require additional research to explain the reasons.

\section{CONCLUSIONS}

The study of psychopathological reaction features in parents of children suffering from chronic pathology of musculoskeletal system revealed a wide range of symptoms, which are based on anxiety-depressive disorders, as well as astheno-apathetic, obsessive and dyssomnic manifestations, as well as signs of neurotization with an increase in disease duration. Mothers showed higher levels of depression and anxiety, while fathers exhibited higher levels of aggressiveness; marked psychopathological reactions in mothers are found even with a short disease duration in children, whilst in fathers they grow significantly with an increase in disease duration.

\section{REFERENCES}

1. Muscara F., McCarthy M.C., Hearps S.J.C. et al. Trajectories of Posttraumatic Stress Symptoms in Parents of Children With a Serious Childhood Illness or Injury. J Pediatr Psychol. 2018; 43(10): 1072-1082.

2. Winston F.K., Kassam-Adams N., Vivarelli-O'Neill C. et al. Acute Stress Disorder Symptoms in Children and Their Parents After Pediatric Traffic Injury. Pediatrics. 2002; 109(6): e90.

3. Stremler R., Haddad S., PullenayegumE.,Parshuram C. Psychological Outcomes in Parents of Critically III Hospitalized Children. J Pediatr Nurs, 2017;34:36-43.

4. KapfhammerH.P.Depressive, Anxiety and Posttraumatic Stress Disorders as LongTerm Sequelae of Intensive Care Treatment. Nervenarzt. 2016; 87(3): 253-263.

5. Nelson L.P., Gold J.I. Posttraumatic Stress Disorder in Children and Their Parents Following Admission to the Pediatric Intensive Care Unit: A Review. Pediatr Crit Care Med. 2012; 13(3): 338-347.

6. Boman K.K., Kjällander Y., Eksborg S., Becker J. Impact of Prior Traumatic Life Events on Parental Early Stage Reactions Following a Child's Cancer. PLoS One. 2013; 8(3): e57556.

7. De Young A.C., Hendrikz J., Kenardy J.A. et al. Prospective Evaluation of Parent Distress Following Pediatric Burns and Identification of Risk Factors for Young Child and Parent Posttraumatic Stress Disorder. J Child Adolesc Psychopharmacol. 2014; 24(1): 9-17. 
8. Muscara F., McCarthy M.C., Thompson E.J. et al. Psychosocial, Demographic, and IIIness-Related Factors Associated With Acute Traumatic Stress Responses in Parents of Children With a Serious Illness or Injury. J Trauma Stress. 2017; 30(3): 237-244.

9. Melnyk B.M., Alpert-Gillis L., Feinstein N.F. et al. Creating Opportunities for Parent Empowerment: Program Effects on the Mental health/coping Outcomes of Critically III Young Children and Their Mothers. Pediatrics. 2004; 113(6): e597-607.

10. Muscara F., McCarthy M.C., WoolfC. et al. Early Psychological Reactions in Parents of Children With a Life Threatening Illness Within a Pediatric Hospital Setting. Eur Psychiatry. 2015; 30(5): 555-561.

11. Hamilton M. A rating scale for depression by Max Hamilton. Journal of Neurology, Neurosurgery, Psychiatry. 1960; 23: 56-62.

12. Hamilton $M$. The assessment of anxiety states by rating. British Journal of Medical Psychology. 1959; 32: 50-55.

13. Buss A.H., Durkee A. An inventory for assessing different kind of hostility. Journal of Consulting Psychology. 1957; 21: 343-349.

ORCID and contributionship:

Oleksandr Belov: 0000-0002-0156-0777 ${ }^{A, C, D}$

Yevhen Loiko: 0000-0003-3719-186X ${ }^{A, B, D, F}$

Iryna Mazaikina: 0000-0002-8834-8858 B,D,E

Iryna Pototska: 0000-0001-7723-9587 B,D,F

\section{Conflict of interest:}

The Authors declare no conflict of interest.

\section{CORRESPONDING AUTHOR Iryna Pototska}

National Pirogov Memorial Medical University

56 Pirogov St., 21018 Vinnytsia, Ukraine

tel: +380984771945

e-mail:0sobiste8@gmail.com

Received: 24.09 .2020

Accepted: 02.08.2021

A - Work concept and design, B - Data collection and analysis, C - Responsibility for statistical analysis,

D-Writing the article, $\mathbf{E}$-Critical review, $\mathbf{F}$ - Final approval of the article 